\title{
Protein Phosphatase 1 Regulates Human Cytomegalovirus Protein Translation by Restraining AMPK Signaling
}

\section{Carmen Stecher ${ }^{1 *}$, Sanja Marinkov ${ }^{1+}$, Lucia Mayr-Harting ${ }^{1+}$, Ana Katic ${ }^{1+}$, Marie-Theres Kastner ${ }^{1}$, Franz J. J. Rieder-Rommer ${ }^{1}$, Xionghao Lin ${ }^{2}$, Sergei Nekhai ${ }^{2}$ and Christoph Steininger ${ }^{1 *}$}

${ }^{1}$ Division of Infectious Diseases and Tropical Medicine, Department of Medicine I, Medical University of Vienna, Vienna, Austria, ${ }^{2}$ Center for Sickle Cell Disease, Howard University, Washington, DC, United States

Human cytomegalovirus (HCMV) carries the human protein phosphatase 1 (PP1) and other human proteins important for protein translation in its tegument layer for a rapid supply upon infection. However, the biological relevance behind PP1 incorporation and its role during infection is unclear. Additionally, PP1 is a difficult molecular target due to its promiscuity and similarities between the catalytic domain of multiple phosphatases. In this study, we circumvented these shortcomings by using 1E7-03, a small molecule protein-protein interaction inhibitor, as a molecular tool of noncatalytic PP1 inhibition. 1E7-03 treatment of human fibroblasts severely impaired HCMV replication and viral protein translation. More specifically, PP1 inhibition led to the deregulation of metabolic signaling pathways starting at very early time points post-infection. This effect was at least partly mediated by the prevention of AMP-activated protein kinase dephosphorylation, leading to elongation factor 2 hyperphosphorylation and reduced translation rates. These findings reveal an important mechanism of PP1 for lytic HCMV infection.

Keywords: PP1, HCMV, AMPK, phosphatase, tegument, eEF2

\section{INTRODUCTION}

The Ser/Thr protein phosphatase 1 (PP1) is conserved from yeast to humans and abundant in many cell types. PP1 is estimated to dephosphorylate the majority of Ser/Thr-linked phosphorylations on eukaryotic proteins (Heroes et al., 2013). This implies that PP1 counteracts hundreds of distinct Ser/Thr kinases, which is reflected in its functional diversity. Unsurprisingly, catalytic inhibition of PP1 and other phosphatases is highly toxic (Munday, 2013), making them challenging drug targets. However, PP1 exerts its functions as a holoenzyme composed of a catalytic subunit complexed with one of over 200 recognized regulatory proteins (PP1R), interacting with PP1 via docking motifs such as the RVxF, SpiDoc, SILK, IDoHA, or MyPhonE motifs (Shi, 2009; Rebelo et al., 2015). Several viruses exploit this regulatory mechanism by expressing viral PP1Rs to benefit their own replication. Specific viral PP1 targeting proteins promote eIF2 $\alpha$ dephosphorylation, such as Herpes simplex virus 1 ICP34.5 (Li et al., 2011), or African swine fever virus DPL71 protein (Zhang et al., 2010). Measles virus was shown to inhibit antiviral type I interferon production by targeting PP1, and thus preventing RIG-I like receptor and MDA5 dephosphorylation and activation (Davis et al., 2014). Importantly, targeting the RVxF-pocket of PP1 by using the non-catalytic small molecule 
inhibitor 1E7-03 was shown to have an antiviral effect against HIV-1 and several RNA viruses (Ammosova et al., 2014, 2018; Baer et al., 2016; Carey et al., 2018; Tigabu et al., 2018), highlighting the compound as a promising broad-spectrum antiviral candidate. Human cytomegalovirus (HCMV), a dsDNA member of the betaherpesvirus sub-family, is a widespread opportunistic pathogen that can cause serious illness in newborns and immunocompromised patients, especially organ transplant recipients (Sweet, 1999). HCMV manipulates protein translation in its favor without inhibiting total protein synthesis, e.g., by UL38-mediated mTORC1 activation (Moorman et al., 2008), and in contrast to most viruses depends on an increased abundance of cellular ribosomes and protein translation factors (McKinney et al., 2014). Metabolic manipulation starts immediately with HCMV entry and the induction of growth factor receptor signaling (Soroceanu et al., 2008). Furthermore, HCMV employs multiple mechanisms to maintain and promote protein translation while coping with cellular energy stress, e.g., by controlling ribosomal initiation and elongation factors, or metabolic signaling pathways such as PI3K and mTOR (Vincent et al., 2016). It is known that HCMV packages human PP1 from the infected host cell into the tegument of its mature viral particles (Michelson et al., 1996). After viral entry, the phosphatase is then released into the newly infected cell (Michelson et al., 1996). The ensuing cellular hypophosphorylation is further sustained by viral upregulation of PP1 in the host cell (McKinney et al., 2014). Similarly, HCMV tegument proteins are also hypophosphorylated (Rieder et al., 2017b). However, the role of PP1 in HCMV infection is still unknown. In this study, we investigated the role of PP1 during HCMV infection by using a small molecule proteinprotein interaction inhibitor as a molecular tool of noncatalytic PP1 inhibition.

\section{MATERIALS AND METHODS Cell Culture}

Human foreskin fibroblasts (HFF, kindly supplied by Dr. Thomas Mertens, University Ulm, Germany) between passages 8 and 25, ARPE-19 retinal pigment epithelial cells (ATCC CRL-2302) and HeLa cells (kindly supplied by Prof. Johannes Berger, Medical University of Vienna) were cultured under standard conditions $\left(37^{\circ} \mathrm{C}, 5 \% \mathrm{CO}_{2}\right)$ in Dulbecco's modified eagle medium (DMEM GlutaMAX, Gibco) supplemented with $10 \%$ fetal calf serum (FCS, Gibco) and penicillinstreptomycin mix (Gibco) at a final concentration of 100 $\mathrm{U} / \mathrm{mL}$. For PP1 inhibition experiments, cells were pre-treated with 1E7-03 or DMSO for $30 \mathrm{~min}$ before infection or mock infection. 1E7-03 was then kept in the medium at a constant concentration throughout the experiment. Media and treatment were resupplied to the cells after $48 \mathrm{~h}$. 1E7-03 (purity above 98\%) was synthesized by Enamine LTD (Kiev, Ukraine) as described previously (Ammosova et al., 2014), dissolved in DMSO at a stock solution of $20 \mathrm{mM}$ and stored at $-80^{\circ} \mathrm{C}$.

\section{HCMV Infection}

HCMV strain AD169 was prepared as described previously (Rieder et al., 2017a). For virus production, HFF were grown to confluence and subsequently infected with HCMV AD169 at a multiplicity of infection (MOI) of 0.01 . The viral inoculum was replaced by culture medium after $90 \mathrm{~min}$. Upon visibility of a total cytopathic effect (CPE) (usually 8-10 days post-infection), the viral supernatant was harvested and stored at $-80^{\circ} \mathrm{C}$. After thawing, cell debris was removed by centrifugation at $3,000 \mathrm{~g}$ for $20 \mathrm{~min}$. Infectivity of the viral inoculum was then measured using a plaque assay as described elsewhere (Britt, 2010). For functional plaque reduction assays, HFF were seeded into 24well plates and pre-treated with vehicle (DMSO) or 1E7-03 for $30 \mathrm{~min}$ at the indicated concentrations. The cells were then incubated with viral inoculum at 60 plaque forming units per well for $90 \mathrm{~min}$, maintaining a constant concentration of DMSO or 1E7-03 through all phases of the experiment. Ganciclovir (Merck Millipore) was added at the indicated concentrations after removal of the inoculum. The cells were then overlaid with growth medium containing $0.5 \%$ low-melting point agarose. After solidification of the agarose layer, the plates were incubated for 10 days at $37^{\circ} \mathrm{C}$ in a $\mathrm{CO}_{2}$ incubator, then fixed with $2 \%$ formaldehyde and analyzed for number of plaques after staining with $0.02 \%$ methylene blue. Plaque numbers were normalized to the mean of DMSO-treated control samples. IC50 values were calculated with Graphpad Prism (dose-response inhibition). For infection of cell cultures with HCMV strains AD169 or TB40, cells were seeded into 6-well plates, starved overnight in FBS-free growth medium, and pre-treated with the indicated compounds. Viral inoculum was added to the cells at an MOI of 1, if not indicated otherwise, incubated for $1 \mathrm{~h}$ at $37^{\circ} \mathrm{C}$ and then replaced with fresh growth medium including $2 \%$ FBS.

For virion purification, supernatant of infected cells was first pre-cleared by centrifugation for $20 \mathrm{~min}$ at $3,000 \mathrm{~g}, 16^{\circ} \mathrm{C}$. The viral suspension was then ultracentrifuged over a $20 \%$ sucrose $(\mathrm{w} / \mathrm{v})$ cushion at $70,000 \mathrm{~g}$ for $40 \mathrm{~min}$ at $16^{\circ} \mathrm{C}$. Virus pellets were resuspended in urea lysis buffer $(10 \mathrm{mM}$ Tris, $4 \mathrm{M}$ urea, $100 \mathrm{mM}$ $\mathrm{NaH}_{2} \mathrm{PO}_{4}, \mathrm{pH} 7.4,1 \%$ Halt protease and phosphatase inhibitor) and sonicated for $4 \times 10 \mathrm{~s}$. Protein concentration was measured using a Pierce $660 \mathrm{~nm}$ assay before addition of Laemmli loading dye and SDS-PAGE.

\section{RNA Isolation and RT-qPCR}

Total RNA was extracted from cells using the PureLink RNA mini kit (Thermofisher Scientific) according to the manufacturer's instructions, including a 15-min on-column DNA digest using an RNAse-free DNase kit (Qiagen). First strand cDNA was synthesized using iScript reverse transcriptase (Biorad), which includes a mix of oligo-dT and random hexamer primers. Quantitative reverse transcription PCR (qRT-PCR) was performed using a StepOne Plus Real-Time PCR System (Applied Biosystems) and Applied Biosystems' Power SYBR Green Master Mix. Sequence-specific oligonucleotide primers were designed using Primer3Plus (Untergasser et al., 2007) or obtained from RTprimer-DB (Pattyn et al., 2003) or PrimerBank (Spandidos et al., 2010) and synthesized by Microsynth (Austria). Relative expression values were normalized to human 
GAPDH (glyceraldehyde-3-phosphate dehydrogenase) using the comparative threshold cycle method $[2-\Delta \mathrm{Ct}$ (Schmittgen et al., 2008)], or $2-\Delta \Delta \mathrm{Ct}$ (Livak and Schmittgen, 2001) for comparison of mRNA expression between samples (e.g., infected vs. mockinfected). Primers used are described in Supplementary Table 1.

\section{SDS-PAGE and Western Blot}

For protein harvest of whole cell lysates, cells were washed with PBS and lysed in lysis buffer (50 mM Tris pH 7.5, $500 \mathrm{mM} \mathrm{NaCl}$, $1 \%$ NP-40, $0.1 \%$ SDS) supplemented with $1 \%$ Halt protease and phosphatase inhibitor (Thermofisher). Protein concentration of lysates was determined using the Pierce BCA protein assay kit (Thermofisher). Equal amounts $(10-30 \mu \mathrm{g})$ of sample were loaded onto self-cast $6 / 8 \%$ polyacrylamide gels or $4-15 \%$ precast Mini Protean TGX polyacrylamide gradient gels (Biorad) and subjected to SDS-PAGE. Proteins were blotted to a $0.45 \mu \mathrm{m}$ PVDF membrane (Thermofisher) and subsequently stained with Ponceau S solution for total protein visualization. Destained membranes were blocked with StartingBlock TBS blocking buffer (Thermofisher) and subsequently probed with primary antibody overnight at $4{ }^{\circ} \mathrm{C}$. The monoclonal antibodies p-AMPK $\alpha$ T172 \#50081, AMPK $\alpha$ \#5831, AMPK $\beta 1$ \#12063, b-actin \#8457, pEEF2 T56 \#2331, p-EEF2K S366 \#3691, p-eIF2 $\alpha$ S51 \#9721, peIF4e S2019 \#9741, eIF4e \#2067, p-Raptor S792 \#2083, Raptor \#2280, RXR $\alpha$ 3085, p-ULK1 S555 \#5869, ULK1 \#8054, and secondary goat $\alpha$-Rabbit HRP \#7074 were obtained from Cell Signaling Technology. The monoclonal antibodies eEF2K sc390710, EEF1G sc-393378, EEF2 sc-166415, EF-Tu (EEF1A) sc393924, GAPDH sc-47724, HCMV pp65 sc-56976, pp72 sc69834, pp72/86 sc-69748, pp86 sc-69835, eIF2 $\alpha$ sc-133132, PP1 (E-9) sc-7482, PP1 $\alpha$ sc-271762, PP1 $\beta$ sc-373782, and PP1 $\gamma$ sc-515943 were from Santa Cruz Biotechnologies. Secondary goat anti-mouse HRP antibody was from Biorad (1706516). Isoform specificity of antibodies was validated elsewhere (Hiraga et al., 2017). The UL32/pp150 IgG2b monoclonal antibody was synthesized from hybridoma cell lines and stems from mice immunized with the XP1 antigen expressed in E. coli as described previously (Hensel et al., 1995).

\section{Phos-TAG SDS-PAGE}

For phosphorylation-specific separation of proteins, pre-cast SuperSep Phos-Tag 7.5\% $(50 \mu \mathrm{M})$ gels (Wako Fujifilm) were used for SDS-PAGE. Gels were run at constant current of $15 \mathrm{~mA}$ for $3 \mathrm{~h}$, then washed $6 \times 10 \mathrm{~min}$ in Tris/Glycine buffer containing $10 \mathrm{mM}$ EDTA and equilibrated for $2 \times 10 \mathrm{~min}$ in Tris/Glycine buffer containing $1 \mathrm{mM}$ EDTA. Proteins were blotted to a PVDF membrane overnight at $24 \mathrm{~V}$.

\section{Co-immunoprecipitation}

For co-immunoprecipitation (Co-IP) of AMPK and PP1, HeLa cells were transfected with a total of $25 \mu \mathrm{g}$ pcDNA-His-PP1$\mathrm{H} 248 \mathrm{~K}$ and pcDNA-AMPK $\beta 1$ using the Turbofect lipofection reagent (Thermofisher) and Optimem serum-free medium (Gibco). Cells were lysed $48 \mathrm{~h}$ after transfection $(50 \mathrm{mM}$ Tris $\mathrm{pH}$ 7.5, $500 \mathrm{mM} \mathrm{NaCl}, 1 \% \mathrm{NP}-40,0.1 \%$ SDS, and freshly supplemented protease inhibitor cocktail), spinned for $10 \mathrm{~min}$ at $10,000 \mathrm{~g}$ and immediately diluted with $1 \mathrm{x}$ TBS after taking aliquots for input and protein concentration measurement using the Pierce BCA assay. Co-IP was performed by the addition of $2 \mu \mathrm{g}$ of the respective antibody (6x-His Tag HIS.H8 MA1-21315 from Invitrogen, control IgG from Santa Cruz Biotechnology or AMPK $\beta 1$ from Cell Signaling) for $1 \mathrm{~h}$, followed by the addition of Protein A/G Plus beads (Santa Cruz Biotechnology) for another $2.5 \mathrm{~h}$. Beads were then washed multiple times over spin columns, followed by elution by boiling in SDS-PAGE loading dye for 5 min. Light-chain-specific secondary HRP-conjugated antibodies (Santa Cruz Biotechnology) were used for the ensuing Western Blot detection.

\section{Nano-LC-FT/MS Analysis}

LC-FT/MS analysis was performed on a LC-20AD nano-HPLC system (Shimadzu Corporation, Columbia, MD, USA) coupled to a LTQ XL Orbitrap mass spectrometer (Thermofisher) running with Xcalibur software (version 2.0.7, Thermofisher). Processed peptides or phosphopeptides were resuspended in $50 \mu \mathrm{L}$ water with $0.1 \%$ formic acid (v/v). $10 \mu \mathrm{L}$ of sample was loaded and analyzed using an in-house C18-packed analytical column (25 $\mathrm{cm} \times 150 \mu \mathrm{m}, 5 \mu \mathrm{m}, 200 \AA$, Michrom Bioresources, Auburn, CA, USA). Mobile phase A was $0.1 \%$ formic acid in water, while mobile phase B was $0.1 \%$ formic acid in acetonitrile. Samples were separated with a linear gradient of 6-55 min, 2$40 \% \mathrm{~B}, 55-62 \mathrm{~min}, 40-80 \% \mathrm{~B}, 62-70 \mathrm{~min}$, and $80 \% \mathrm{~B}(\mathrm{v} / \mathrm{v})$ at the flow rate of $600 \mathrm{~nL} / \mathrm{min}$. The Orbitrap was operated under data-dependent acquisition mode. Spray voltage, capillary temperature, and capillary voltage were set to $2.0 \mathrm{kV}, 200^{\circ} \mathrm{C}$, and $39.5 \mathrm{~V}$, respectively. Full-scan mass spectra were acquired in Orbitrap over $300-2,000 \mathrm{~m} / \mathrm{z}$ with a resolution of 30,000 , followed by MSn scans by CID activation mode. The three most intense ions were selected for fragmentation using collisioninduced dissociation (CID) in the LTQ.

\section{Proteomics}

Proteins (150 $\mu \mathrm{g}$ per group) extracted from DMSO or 1E703-treated HFF cells infected with HCMV were ultrasonically suspended in sodium phosphate buffer $(\mathrm{pH} 8.0)$, reduced in $10 \mathrm{mM}$ dithiothreitol $\left(1 \mathrm{~h}\right.$ at $\left.60^{\circ} \mathrm{C}\right)$, alkylated with $30 \mathrm{mM}$ iodoacetamide (20 min, room temperature in the dark), and digested with $10 \mu \mathrm{g}$ trypsin (Promega) at $37^{\circ} \mathrm{C}$ on an orbital shaker overnight. Peptide mixtures from each group were divided into two equal parts. One half was directly purified by Pierce Graphite Spin Columns (88302, Thermofisher) following the manufacturer's instructions and analyzed by LC-FT/MS. Label-free quantitative analysis was performed on Proteome Discoverer 2.4 (PD 2.4) using Sequest search engine (Thermo Fisher Scientific), against the Uniprot Human database at a false discovery cut off $\leq 1 \%$. Filter settings to define peptide confidence were as follows: charge $2=1.5$ (XCorr score), charge $3=2.0$, and charges $>4=2.5$ for high confidence peptides; charge $2=0.5$, charge $3=0.8$, and charges $>4=1$ for modest confidence peptides. The other half of peptide mixtures were enriched by high-select $\mathrm{TiO}_{2}$ phosphopeptide enrichment kit (88301, Thermofisher). $\mathrm{TiO}_{2}$ spin columns were prepared by washing with $20 \mu \mathrm{L}$ of $0.4 \%$ TFA in $80 \%$ acetonitrile and $20 \mu \mathrm{L}$ of $25 \%$ lactic acid. Peptide mixtures were dried, resuspended in 
$150 \mu \mathrm{L}$ of $25 \%$ lactic acid, added to $\mathrm{TiO}_{2}$ spin columns, and incubated for $2 \times 10 \mathrm{~min}$ with end-over-end rotation. Samples were washed with $20 \mu \mathrm{L}$ of $25 \%$ lactic acid and $20 \mu \mathrm{L}$ of $25 \%$ lactic acid twice. Then samples were eluted using $50 \mu \mathrm{L}$ of $1.5 \%$ ammonium hydroxide and $50 \mu \mathrm{L}$ of $5 \%$ pyrrolidine. The elution fractions were combined, acidified by adding 100 $\mu \mathrm{L} 2.5 \%$ TFA, and purified using graphite spin columns. The enriched phosphopeptides were then submitted to LC-FT/MS analysis. LC-FT/MS raw data were searched by PD 2.4 using the Sequest search engine (Thermofisher), against the Human Uniprot database at a false discovery cutoff $\leq 1 \%$. A maximum of two missed cleavage sites was allowed. The mass tolerance for the precursor ion was set on $30 \mathrm{ppm}$ and for the fragment on 0.1 Da. Phosphorylation of serine, threonine, and tyrosine was enabled as dynamic modifications, while carbamidometylation of cysteine was set as fixed modification. The same filter settings as above were used to determine the peptide confidence. The label-free quantification of phosphopeptides was performed with SIEVE 2.1 software (Thermofisher). Principal component analysis and volcano plots were exported from PD 2.4. and adapted graphically. The mass spectrometry proteomics data have been deposited to the ProteomeXchange Consortium via the PRIDE repository with the dataset identifier PXD023598.

\section{Protein Array}

The Proteome Profiler Human Phospho-Kinase Array Kit (R\&D Systems) was used according to the manufacturer's instructions. The array membranes were incubated with $300 \mu \mathrm{g}$ cell lysate overnight. The detected signals were quantified using ImageLab software (BioRad). The signal of the negative control was subtracted from each spot, and values were normalized to the reference spots in each membrane.

\section{Translation Assays}

Protein synthesis was assayed in black-wall 96-well plates using O-propargyl-puromycin (OPP) labeling for $30 \mathrm{~min}$ at $37^{\circ} \mathrm{C}$ followed by Click-iT chemistry using a Click-iT Plus OPP Alexa Fluor 647 Protein Synthesis Assay Kit (Invitrogen) as detailed by the manufacturer. Cells were pre-treated with 1E703, cycloheximide (Santa Cruz Biotechnology), or DMSO for 30 min before OPP addition. In HCMV samples, infection was let to proceed for $4 \mathrm{~h}$ in the presence of DMSO or 1E703 before the addition of OPP. Fluorescence was quantified using a Varioskan plate reader with excitation/emission bands of 650/670 nm for AF647 and 350/451 nm for NuclearMask Blue Fluorescence, respectively. Background fluorescence from the no OPP condition was subtracted from all values. AF647 fluorescence was normalized to the NuclearMask signal to control for cell number.

\section{Mammalian-2-Hybrid Assay}

Mammalian-2-hybrid luciferase assays were performed according to the protocol of the MatchmakerTM system (Clontech) using the pRF-Luc reporter plasmid (Stratagene) for detection of protein-protein interaction. HeLa cells were transfected in 24-well plates using $2 \mu$ l Turbofect (Thermofisher) and 850 ng DNA per well according to the manufacturer's instructions. The following plasmid combinations were transfected: $0.1 \mu \mathrm{g}$ of luciferase reporter plasmid pFR-Luc (Stratagene) and $0.05 \mu \mathrm{g}$ of pCMV- $\beta$-Gal (P204, Promega) for normalization, combined with $0.35 \mu \mathrm{g}$ of bait (pM, GAL4DBD encoding) and $0.35 \mu \mathrm{g}$ of prey (pVP16, VP16AD encoding) plasmids (cloning vectors kindly supplied by Markus Kunze, Medical University of Vienna). After $48 \mathrm{~h}$, transfected cells were washed with PBS and lysed in $100 \mu \mathrm{l} /$ well 1x Cell Culture Lysis Reagent (Luciferase Assay System; Promega). Cell lysates were centrifuged at $13,000 \mathrm{rpm}$ at $4^{\circ} \mathrm{C}$ for $20 \mathrm{~min}$, and the supernatant was tested for luciferase and $\beta$-galactosidase activity. For luminescence measurements, luciferase activity was tested using a Varioskan Lux microplate reader (Thermofisher) by well-loop addition of $50 \mu$ l substrate (Luciferase Assay Reagent; Promega) to $10 \mu \mathrm{l}$ lysate and immediate detection of luminescence. $\beta$ Galactosidase content was tested by incubation of cell lysates with 2-Nitrophenyl- $\beta$-D-galactopyranoside (ONPG; Sigma) at $37^{\circ} \mathrm{C}$ and measurement of absorbance at $420 \mathrm{~nm}$ in a microplate reader. Luminescence values were normalized to $\beta$-galactosidase to account for transfection efficiency (Kunze et al., 2015). Expression of bait and prey proteins was controlled for by verifying GFP fluorescence of pM-bait-eGFP transfected cells and bait/prey protein detection via western blot.

\section{siRNA Transfections}

EEF2k-targeting siRNAs, AMPK-targeting siRNAs, and scrambled control siRNA siCTRL (Hait et al., 2006; Ashour et al., 2014; Li et al., 2014; Bae et al., 2019) were produced by Microsynth (Austria) with 3' dTdT overhangs, and PP1-specific siRNA mixes were obtained from Santa Cruz Biotechnology (see Supplementary Table 2). For transfections, HFF were seeded into 6-well plates and transfected at $80 \%$ confluence with a mixture of $50 \mathrm{nM}$ siRNA and $5 \mu \mathrm{l}$ Turbofect (Thermofisher) diluted in serum-free Optimem medium (Thermofisher). Five hours after transfection, cells were washed and the medium was replaced with fresh growth medium. After $24 \mathrm{~h}$, cells were transfected a second time. Another $24 \mathrm{~h}$ later, HFF were infected with HCMV AD169 and harvested at $24 \mathrm{~h}$ post-infection for analysis of viral protein expression by western blot.

\section{Phosphatase Assays}

For in vitro dephosphorylation assays, whole cell lysates were incubated with bacterial Lambda phosphatase $(\lambda)$ or protein phosphatase 1 (New England BioLabs) according to the manufacturer, with a maximum of $4 \mathrm{U}$ (PP1) or 5,00 $U(\lambda)$ for $50 \mu \mathrm{g}$ protein. Enzymatic reactions were stopped after $30 \mathrm{~min}$ at $30^{\circ} \mathrm{C}$ by adding reducing sample buffer and boiling for $5 \mathrm{~min}$. All sample conditions contained a protease inhibitor cocktail (Sigma-Aldrich); a protease/phosphatase inhibitor mix (Halt, Thermfisher) was used as an additional control.

\section{Statistical Analyses}

If not indicated otherwise, bar graphs and error bars show the mean \pm standard error of the mean of 3 or more independent experiments. We analyzed the data using Graphpad Prism 7 using the respective statistical analysis and post hoc test indicated 
A

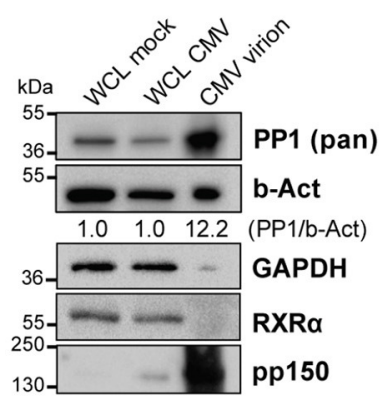

D

$$
\begin{aligned}
& { }^{955} \text { KSSVSNAPPV } \\
& \text { ASPSILKPGASA } \\
& \text { ALQSRRSTGTAA } \\
& \text { VGSPVKSTTGMK } \\
& \text { TVAFDLSSPQKS } \\
& \text { GTGPQP } 1018
\end{aligned}
$$

B

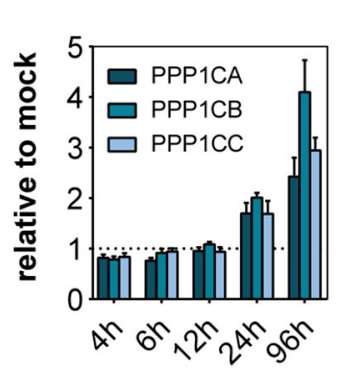

E

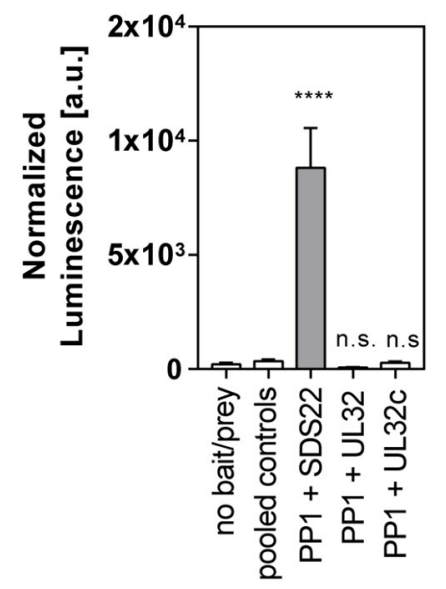

C

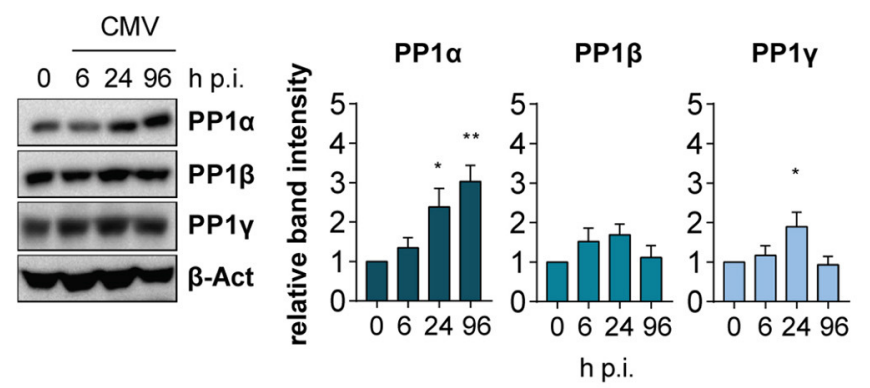

$\mathbf{F}$

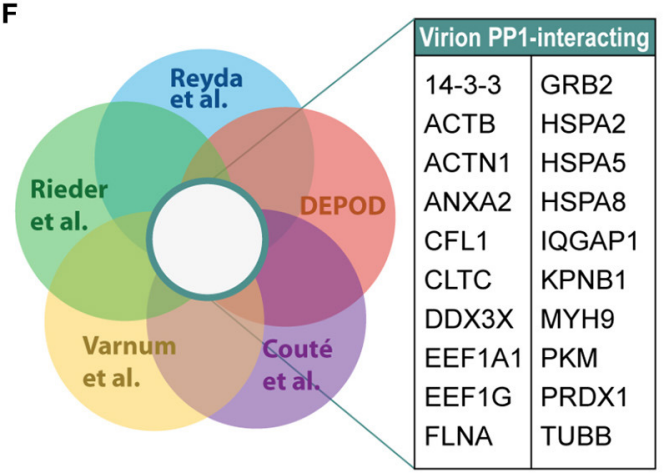

FIGURE 1 | Human PP1 binding proteins in the HCMV virion. (A) Immunoblots showing abundance of the indicated proteins in whole cell lysate (WCL) from mock-infected and HCMV-infected cells at $96 \mathrm{~h}$ p.i. compared to HCMV virion lysate from ultra-centrifuged HCMV AD169. $15 \mu \mathrm{g}$ total protein was loaded in each lane. (B) Expression of PP1 isoform mRNA shown as fold change compared to mock at the indicated time points post-infection with HCMV AD169 at MOI 3. Representative of 3 independent experiments. (C) Western blots showing PP1 isoform specific staining (Hiraga et al., 2017) of mock or HCMV AD169 infected cells ( $\mathrm{MOI} 3$ ) at the indicated time points post-infection. (D) Sequence of HCMV UL32 protein C terminus containing SILK (yellow) and RVxF (red) motifs. (E) Mammalian-2-hybrid testing protein-protein interaction of PP1 and SDS22 (positive control), UL32, or a c-terminal variant of UL32 (UL32c) containing the SILK and RVxF motif. In the no bait/prey negative control, only the luciferase and beta-galactosidase vectors were transfected. For simplicity, all negative bait/prey empty vector control combinations are shown as "pooled controls." Asterisks indicate significant differences from Dunnett's ANOVA post hoc test compared to pooled controls. (F) Venn diagrams showing the gene name list of intersection between the indicated MS Datasets (Varnum et al., 2004; Reyda et al., 2014; Rieder et al., 2017b; Couté et al., 2020) and the PP1 interactor list from DEPOD (PP1-PPi) (Li et al., 2013).

in the figure legends. An alpha value of 0.05 was considered significant $\left({ }^{\star} p<0.05,{ }^{* *} p<0.01,{ }^{* *} p<0.001\right.$, and $\left.{ }^{* * * *} p<0.0001\right)$.

\section{RESULTS}

\section{The HCMV Virion Is Enriched in Human PP1 and Contains Multiple PP1 Interacting Proteins}

Despite the reported presence of the PP1 catalytic subunit in the HCMV tegument, it is not known how the phosphatase is incorporated into the virion or what is the purpose for the virus to carry it despite tight spatial restriction. Since the substrate specificity of PP1 as a holoenzyme greatly depends on its specific regulatory subunit, we sought to gain insight into the potential composition of the virion-derived PP1 holoenzyme. In fact, we were able to detect all three isoforms, $\mathrm{PP} 1 \alpha, \mathrm{PP} 1 \beta$ and $\mathrm{PP} 1 \gamma$, in virus lysate from HCMV AD169 virions after ultracentrifugation using western blot (Supplementary Figure 1A). While it has been discussed that other macromolecules such as human mRNA present in the virion may merely represent their abundance at the packaging site (Terhune et al., 2004), we observed an enrichment of PP1 in cell-free HCMV lysate: PP1 was present at a higher concentration in virus lysate compared to whole cell lysate of mock-infected or HCMV-infected fibroblasts, in contrast to beta-actin which is also part of the HCMV virion according to multiple studies (Varnum et al., 2004; Reyda et al., 2014; Rieder et al., 2017b). The retinoid X receptor ( $\mathrm{RXR} \alpha$ ) and GAPDH, used as cellular controls abundant in whole cell lysate, were absent from the virion (Figure 1A). HCMV-imported PP1 is hypothesized to cause cellular hypophosphorylation shortly after HCMV attachment (Michelson et al., 1996), and in addition PP1 was reported to be upregulated during HCMV infection (Hakki and Geballe, 2008). In an in vitro infection model using the 
laboratory strain AD169, we confirmed PP1 upregulation at the level of mRNA in the course of infection (Figure 1B). However, only the PP1 $\alpha$ protein isoform, but not $\mathrm{PP} 1 \beta$ and $\mathrm{PP} 1 \gamma$, was consistently and significantly increased during infection as determined by isoform-specific immunoblots (Figure 1C). The PP1 holoenzyme usually involves binding of a regulatory subunit to one or multiple binding pockets via docking on the regulatory protein such as the RVxF, SpiDoc, SILK, IDoHA, or MyPhonE motifs, with the RVxF motif being the most common one occurring in most of the PP1 regulatory proteins and also in the few known viral PP1 binding proteins (Nekhai et al., 2007; Zhang et al., 2010; Li et al., 2011). Thus, as a next step we tested the possibility of direct binding of HCMV tegument proteins to PP1. Of the $38 \mathrm{HCMV}$ proteins that are described to occur in the tegument (reviewed in Kalejta, 2008), 10 contain at least one classical RVxF motif, most of which are not conserved in a closely related betaherpesvirus (Supplementary Figure 1B). Other common linear PP1-docking motifs on HCMV tegument proteins are absent except for a "SILK" motif in the C-terminus of UL32 (Figure 1D). We tested protein-protein interaction between PP1 and RVxF-containing viral tegument proteins using a mammalian-2-hybrid assay; yet we were unable to detect any direct binding of PP1 to UL32 (Figure 1E) and other RVxFcontaining tegument proteins (Supplementary Figure 1C) in this system compared to the positive control SDS22. Thus, we next considered the possibility that PP1 is incorporated into the tegument as a holoenzyme bound to another human protein. Mass spectrometry (MS) analyses of purified HCMV virions from our group and others further indicate that in addition to PP1, HCMV integrates multiple other human proteins into its viral particle. From these data, we have identified 20 human proteins inside the virion that were reported as hits in 4 independent MS datasets (Varnum et al., 2004; Reyda et al., 2014; Rieder et al., 2017b; Couté et al., 2020) and that are also listed in the PP1 interactome according to the DEPOD database (Li et al., 2013) (Figure 1F). This list also contains members of the ribosomal translation elongation factor complex and 14-3-3 proteins, which were validated by western blot (Supplementary Figure 1D).

\section{PP1 Inhibition Is Detrimental for HCMV Replication}

Given the hypothesized importance of PP1 for the virus during infection, we next sought to test the effect of PP1 inhibition on viral propagation. Catalytic PP1 inhibition is toxic to cells already at low molecular levels and unspecific since most PP1 inhibitors also co-target PP2a (Swingle et al., 2007; Munday, 2013). In order to study PP1 function during HCMV infection, we used 1E7-03, a non-catalytic small molecule inhibitor of PP1 that targets the regulatory " $\mathrm{RVxF}$ " -binding pocket of PP1 (see Figure 2A) and that was previously shown to have antiviral activity against HIV-1 and several other RNA viruses (Ammosova et al., 2014, 2018; Baer et al., 2016; Carey et al., 2018; Tigabu et al., 2018). 1E7-03 significantly inhibited HCMV replication in a plaque reduction assay at an average IC50 of $1.8 \mu \mathrm{M} \pm 0.12$ (Figure 2B). As previously reported, 1E7-03 has a low toxicity profile (Ammosova et al., 2014), making it possible to study the cells over longer periods of time. While 1E7-03-treated and mock-infected or HCMV-infected cells showed limited cell death, Calyculin A treated cells died upon prolonged time in culture, even in the absence of HCMV infection (Supplementary Figures 2A-C). Importantly, 1E7-03 treatment did not seem to alter PP1 expression during infection compared to the vehicle control (Supplementary Figure 2D). In order to investigate the mechanism behind 1E7-03-mediated inhibition of HCMV replication, we next tested whether viral transcription and translation of immediate early, early, and late proteins were affected by treatment with 1E7-03. As reported in Figure 2C and Supplementary Figure 2E, mRNA transcription of both immediate early and late genes surprisingly did not significantly change at the time points measured, indicating that viral entry and transcription per se are likely not affected by 1E7-03. However, viral translation was severely attenuated by the treatment, including representatives of immediate early (pp72, pp86), early ( $p$ 65), and late (pp150) proteins throughout the HCMV life cycle, apparent already at the immediate-early expression stage of the HCMV life cycle (Figures 2D,E). We observed a similar reduction of viral immediate early proteins when PP1 was transiently knocked down with specific siRNAs (Figure 2F). The catalytic phosphatase inhibitor Calyculin A also reduced HCMV protein expression (Figure 2G), but HFF showed poor viability upon prolonged time in culture (Supplementary Figures 2A-C). We also observed that starting 1E7-03 treatment later during infection led to a less pronounced downregulation of viral proteins (Supplementary Figure 2F) as well as reduced effectivity in plaque reduction assays (Supplementary Figure 2G). Importantly, a similar effect of 1E7-03 on CMV immediate early protein expression could be observed in retinal pigment epithelial cells infected with the TB40/E CMV strain (Supplementary Figure 2H). Moreover, the reduction of HCMV protein expression by 1E7-03 was dose dependent (Supplementary Figure 2I). These results suggest that $1 \mathrm{E} 7-03$ affects a stage of the HCMV replication cycle that starts before the onset of viral DNA replication, and is able to inhibit the replication HCMV at a low micromolar range.

\section{E7-03 Attenuates Mitogenic Signaling Pathways During Infection}

Given the observed attenuation of viral translation rates and the role of PP1 in cellular metabolism, we next analyzed global translation rates during infection and PP1 inhibition. In a fluorescence-based puromycin assay, we indeed observed slightly attenuated translation rates with 1E7-03 during infection, but not in uninfected cells (Figure $\mathbf{2 H}$ ). We next conducted a proteome and $\mathrm{TiO}_{2}$-enrichment phosphoproteome analysis of HCMV-infected cells treated with vehicle or 1E7-03 and harvested at $2 \mathrm{~h}$ post-infection performed in triplicate. This resulted in 3839 differentially regulated phosphopeptides 


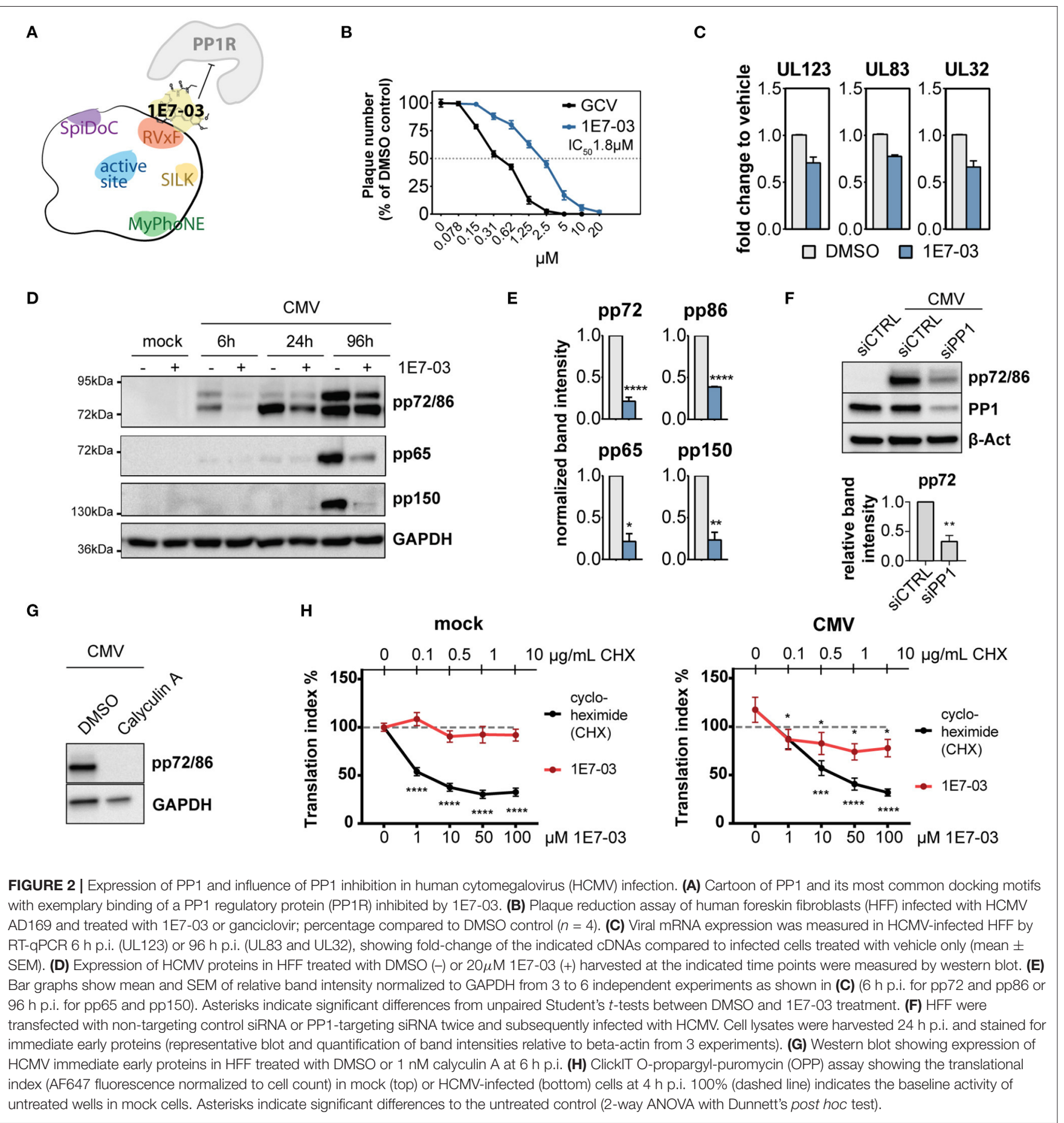

between the vehicle and 1E7-03 group in HCMV-infected cells (Figures 3A-C and Supplementary Material). A pathway enrichment analysis showed that 1E7-03 induced changes in Rho GTPase-dependent cytoskeletal regulation, metabolic stress, and mitogenic signaling pathways (Figures 3D,E). Similarly, a phosphokinase protein array at immediate early times post-infection indicated changes in PI3K/Akt, JNK, and
AMPK mitogenic signaling pathways upon treatment with 1E7-03 (Figure 3F). Specifically, activating phosphorylation of AMPK $\alpha$ and AMPK targets (ULK1, eIF4e, and inhibitory Raptor phosphorylation) was increased by 1E7-03 as determined by phospho-specific western blot (Figure 3G). However, phosphorylation of mTOR seemed not to be affected by 1E7-03 (Supplementary Figure 3). 


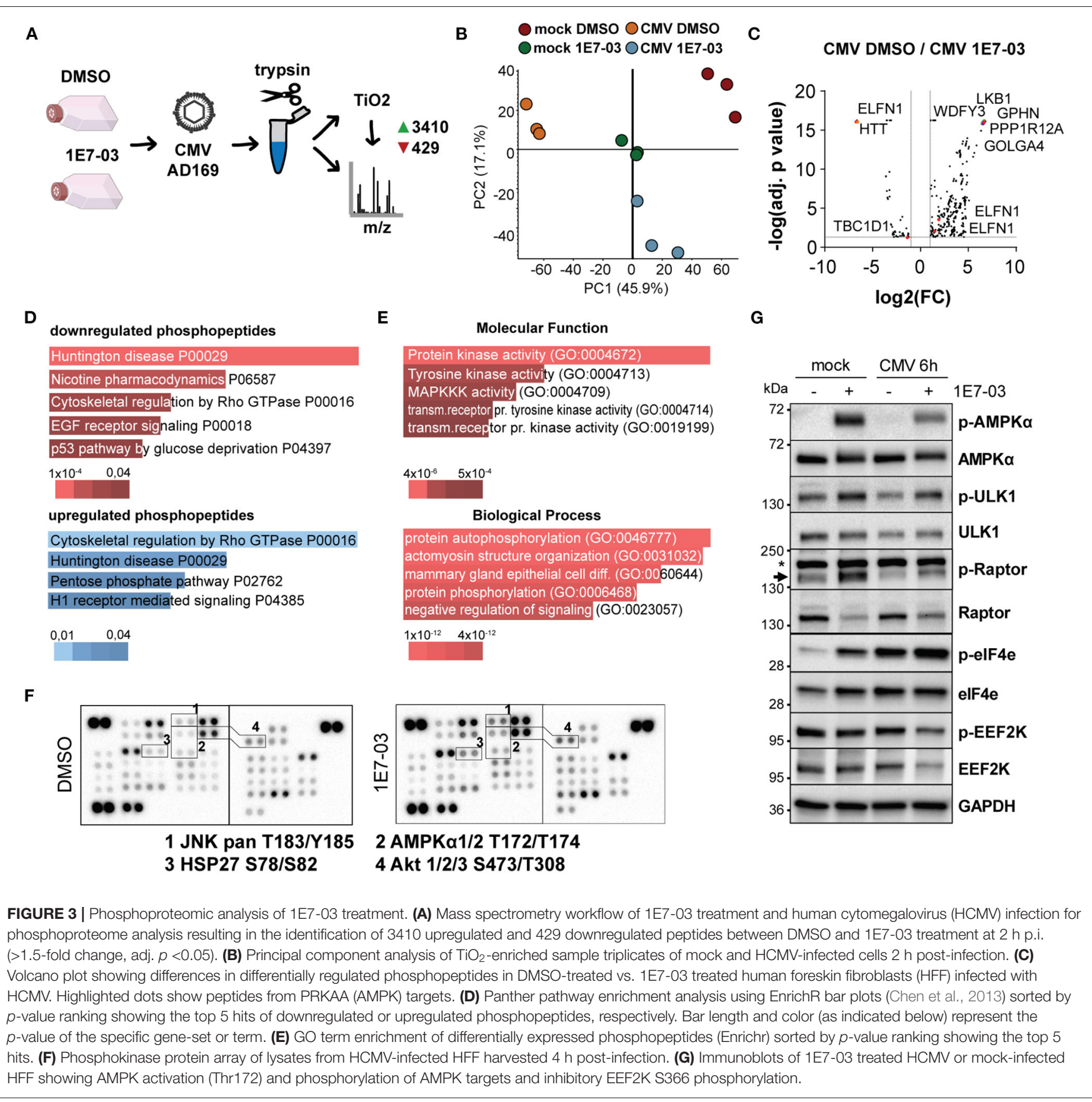

\section{PP1 Is an AMPK Phosphatase and Its Inhibition Leads to AMPK and EEF2 Hyperphosphorylation}

During viral infection, cellular stress pathways are activated in the cell that normally lead to shutdown of protein translation via phosphorylation of translation initiation factor $2 \alpha$ (eIF- $2 \alpha$ ), e.g., by protein kinase R. Targeting eIF- $2 \alpha$ for dephosphorylation by PP1 can re-enable translation, as done by Herpes simplex virus 1 (Li et al., 2011). Thus, we investigated the possibility that HCMV may employ a similar mechanism which might be inhibited upon treatment with PP1-modulators.
However, we detected only minor and transient changes in eIF$2 \alpha$ phosphorylation during HCMV infection upon treatment with 1E7-03 (Supplementary Figure 4A) or downstream ATF4 upregulation (Supplementary Figure 4B). On the other hand, AMPK $\alpha$ phosphorylation was greatly increased by 1E7-03 throughout the infection. Inhibitory phosphorylation of EEF2K, an AMPK target (Johanns et al., 2017), was decreased by the compound (Figure 4A). Furthermore, inhibitory Threonine57 phosphorylation of the elongation factor EEF2 was clearly increased throughout the infection upon PP1 inhibition via 1E703 (Figure 4A). This is especially noteworthy, since EEF2 is part 


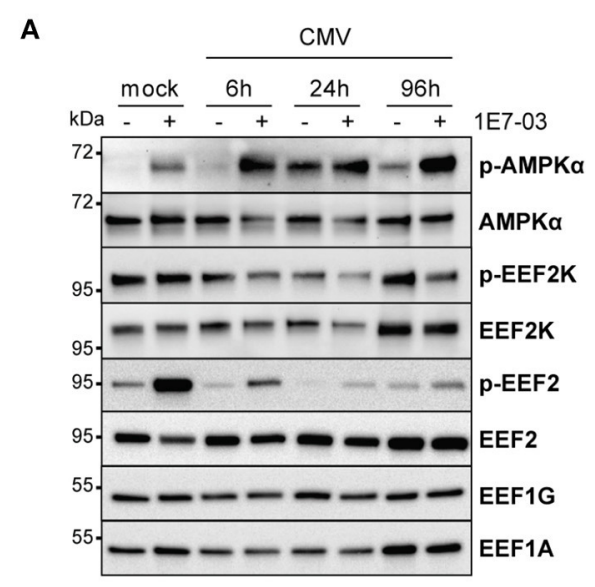

B

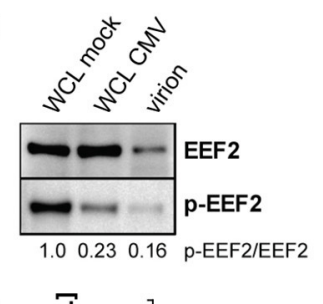

D

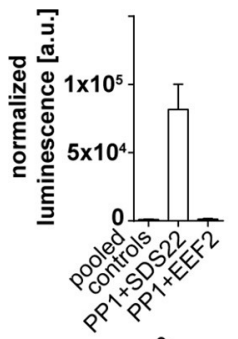

G

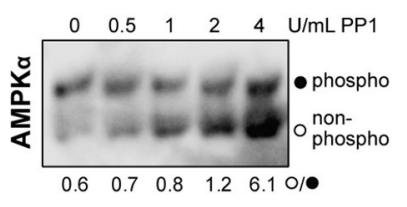

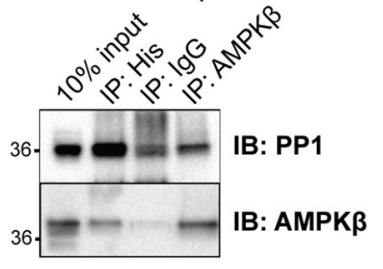

C

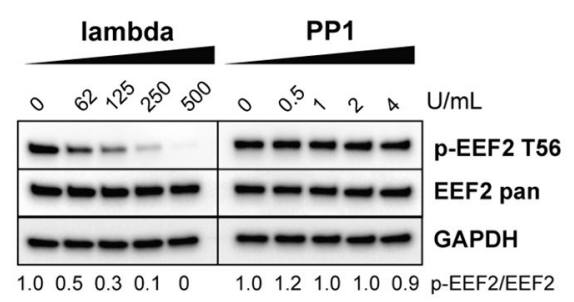

E

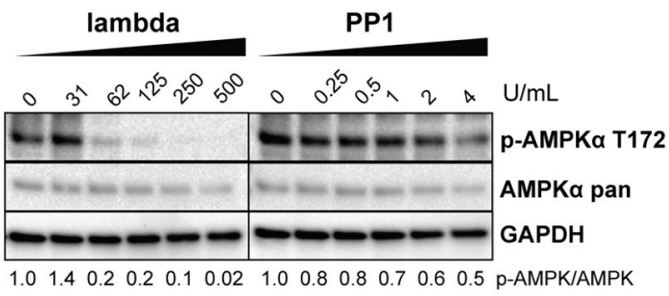

H

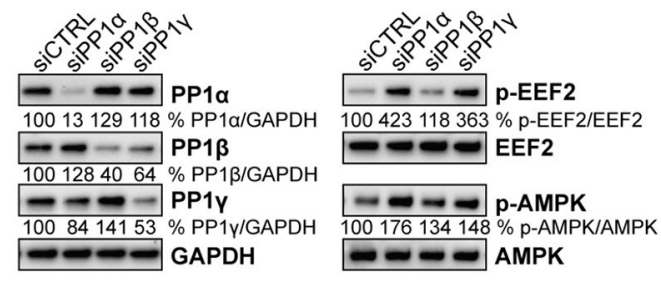

FIGURE 4 | PP1 targets AMPK. (A) Immunoblots showing AMPK and translation elongation factor phosphorylation during human cytomegalovirus (HCMV) infection under treatment of DMSO (-) or 1E7-03 (+). (B) Immunoblots of EEF2 in whole cell lysate of mock- or HCMV infected human foreskin fibroblasts (HFF) and cell-free virus lysate (20 $\mu \mathrm{g}$ protein/lane). (C) in vitro dephosphorylation assay of lysates from FBS and glucose-starved HFF incubated with the indicated amounts of $\lambda$ or PP1 phosphatase. Representative images of p-EEF2 T56-specific western blot are shown. (D) Mammalian-2-hybrid assay of pVP16-PP1 bait and pM-EEF2 or positive control pM-SDS22 prey showing luminescence normalized to beta-galactosidase. For simplicity, all negative empty vector control combinations are shown as "pooled controls." (E) in vitro dephosphorylation assay of lysates from FBS and glucose-starved HFF incubated with the indicated amounts of $\lambda$ or PP1 phosphatase. Representative images of p-AMPK $\alpha$ T172-specific western blot are shown. (F) Lysates from FBS and glucose-starved HFF were incubated with the indicated amounts of PP1 phosphatase in vitro and subsequently separated via Phos-Tag SDS-PAGE. A representative pan-AMPK $\alpha$-specific immunoblot shows the ratio between unphosphorylated and phosphorylated AMPK $\alpha$. (G) Co-immunoprecipitation of His-PP1 and AMPK $\beta$ in lysates of HeLa cells overexpressing a pcDNA-His-PP1 H248K catalytic inactive substrate trap mutant and pcDNA-AMPK $\beta 1$. (H) Representative western blot showing siRNA-mediated knockdown of PP1 isoforms of HFF harvested $24 \mathrm{~h}$ post-CMV infection.

of the human proteins in the HCMV virion, predominantly its dephosphorylated form (Rieder et al., 2017b and Figure 4B). 1E7-03-induced EEF2 and AMPK $\alpha$ phosphorylation started already at concentrations lower than $20 \mu \mathrm{M}$ close to the IC50 of the antiviral effect (Supplementary Figure 4C). Since EEF2 also contains an $\mathrm{RVxF}$ binding motif and is carried in the virion along with PP1, we next investigated whether EEF2 might directly be affected by PP1 inhibition. In order to determine whether EEF2 can be directly phosphorylated by PP1, we performed an in vitro phosphatase assay. However, the addition of exogenous PP1 to cellular lysate was not sufficient for EEF2 dephosphorylation (Figure 4C). Also, EEF2 failed to directly interact with PP1 in a mammalian-2-hybrid assay (Figure 4D). Since we hypothesized that EEF2K is activated upon 1E7-03 treatment as a result of AMPK activation (Figures $\mathbf{3 A}, \mathbf{4 A}$ ), we next explored signaling events upstream of EEF2 phosphorylation affected by PP1 inhibition. The AMPK $\alpha$ subunit, which has been identified as a PP1 substrate in mice (Garcia-Haro et al., 2010), could be dephosphorylated by PP1 in vitro (Figures 4E,F). In addition, we were able to detect PP1 and AMPK $\beta$ in the same complex by CoIP from HeLa cells overexpressing both a PP1 H248K catalytic mutant and AMPK $\beta 1$ (Figure 4G), indicating that PP1 likely targets the AMPK holoenzyme also in human cells. Similar to PP1 inhibition using 1E7-03, also siRNA-mediated knockdown of PP1 led to phosphorylation of AMPK and EEF2 during CMV infection (Figure 4H).

\section{PP1 Is Necessary for Mitogenic Activation via EEF2 in Infected Cells}

To date, EEF2K is the only known kinase for EEF2 T56 phosphorylation. In a knockdown experiment, we therefore attempted to rescue the 1E7-03-induced reduction of viral immediate early proteins by diminishing the accumulation of EEF2 phosphorylation using EEF2K-targeting siRNA mixes. In EEF2K-deficient cells, immediate early protein expression was normal despite the presence of 1E7-03 (Figures 5A,B). Similarly, knockdown of the EEF2K inactivating kinase AMPK led to a reduced effect of 1E7-03 immediate early protein attenuation (Figures 5A,B). 1E7-03 reduced HCMV titers in supernatants harvested from treated cells as determined in a plaque assay using fluorescently labeled virus. This effect was partly reversed in cells with siRNA-mediated inhibition of EEF2K 
A

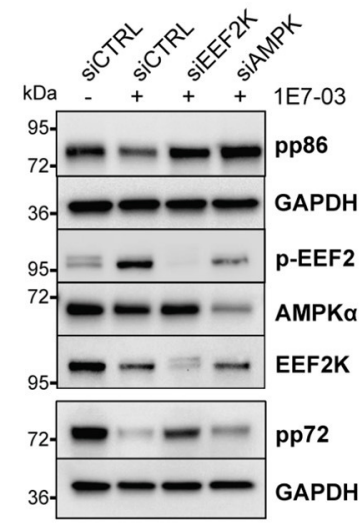

B

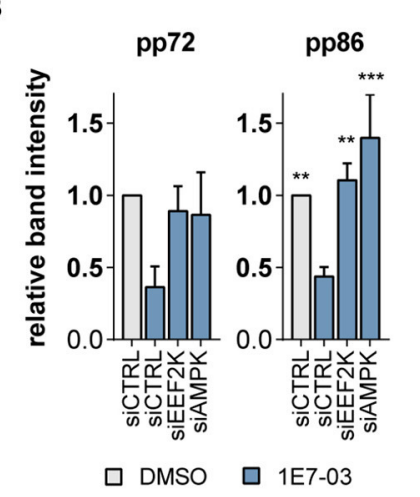

C

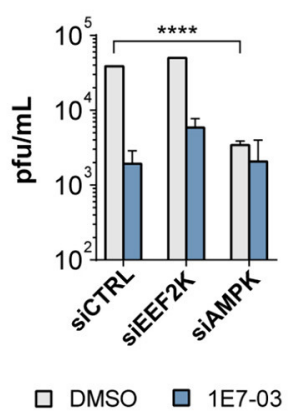

D

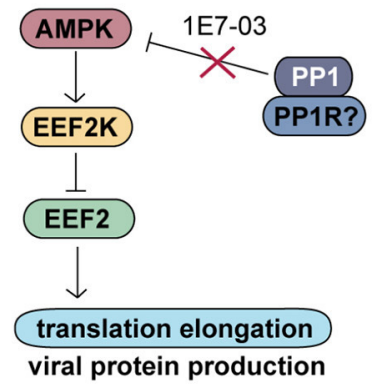

FIGURE 5 | EEF2K knockdown restores viral protein translation. (A) Representative western blot showing non-targeting siRNA (siCTRL) compared to EEF2K and AMPK knockdown in cells infected with human cytomegalovirus (HCMV) and treated with 1E7-03 for 24 h. (B) Quantification of relative band intensities of viral pp86 and pp72 expression at $24 \mathrm{~h} \mathrm{p.i.} \mathrm{as} \mathrm{shown} \mathrm{in} \mathrm{(A)} \mathrm{(} n=3$ for pp86 and $n=2$ for pp72). Asterisks indicate significant differences to control siRNA treated with $1 \mathrm{E} 7-03$ as determined by ANOVA Dunnett's multiple comparison post hoc test ( $p=0.14$ for pp72 ANOVA). (C) Determination of viral titers of cell supernatants of HFF transfected with siRNAs targeting EEF2K or AMPK, treated with DMSO or 1E7-03, and harvested at 96 h post-infection (representative of $n=3$ ). (D) Pathway map showing an overview of the proposed mechanism of PP1 metabolic activation via the AMPK/EEF2K/EEF2 axis inhibited by 1 E7-03.

(Figure 5C), indicating an important role of PP1 in EEF2Kmediated inhibition of infection. However, knockdown of AMPK led itself to impaired production of viral progeny (Figure 5C), in line with previous reports (Terry et al., 2012). A tight and timely regulation of AMPK is likely crucial for HCMV infection since both chemical AMPK activation and inhibition are known to inhibit HCMV propagation (Kudchodkar et al., 2007; Terry et al., 2012; Dunn et al., 2020). In our proposed model, PP1 inhibition by 1E7-03 leads to early AMPK activation and EEF2 inactivation, followed by attenuated translation and inhibition of lytic HCMV infection (Figure 5D).

\section{DISCUSSION}

HCMV produces asymmetric enveloped virions with an extensive tegument layer. The release of the tegument into the cell provides an instant supply of proteins upon lytic infection. As multiple studies have evaluated by now using proteomic techniques, the viral particle contains not only viral, but also many human proteins, many of which are robustly detected across multiple datasets (Varnum et al., 2004; Reyda et al., 2014; Rieder et al., 2017b; Couté et al., 2020). Also the human phosphatase PP1 has been previously described to be part of the tegument layer (Michelson et al., 1996). Here, we show that PP1 is enriched in the virion compared to cellular lysates, implying an incorporation in a directed manner, although we did not discern the role of dense bodies in our experimental setup, and contamination with cellular microvesicles cannot be excluded. However, PP1 has also been detected in highly purified virions (Couté et al., 2020). PP1 specificity depends on the interaction with a regulatory subunit, thus we originally hypothesized that an HCMV tegument protein functions as a PP1 regulatory subunit for incorporation into the virion. When we screened HCMV tegument proteins for potential PP1 binding motifs, the pp150 (UL32) protein stood out containing both an RVxF and a SILK motif. However, we could not confirm an interaction between PP1 and UL32 and several other tegument proteins containing RVxF motifs (Figure 1). We thus hypothesize that PP1 is incorporated as a human holoenzyme from the cell, but cannot exclude a role of other viral proteins. While our experimental setup cannot discern between a role of virusderived vs. cellular PP1 inhibition, we found an essential role of PP1 for HCMV protein translation and replication using the novel PP1 inhibitor 1E7-03 (Figure 2). In contrast to catalytic PP1 inhibition, which mostly co-inhibits PP2a and is highly toxic to cells (Swingle et al., 2007; Munday, 2013), 1E7-03 caused no increased cell death (Supplementary Figure 2), presumably because it does not inhibit the catalytic groove and cannot actively break up existing PP1-PP1R interactions (Lin et al., 2017). This highlights 1E7-03 as a molecular tool for PP1 loss of function experiments over longer periods of time. Importantly, 1E7-03 inhibited HCMV at similar effective concentrations that are necessary to specifically inhibit protein-protein interactions between PP1 and RVXF-harboring regulatory proteins (Lin et al., 2019). From a stoichiometric point of view, the amount of virion-derived PP1 is supposably insignificant compared to the abundance of cellular phosphatases, and the majority of 1E7-03targeted PP1 is likely cellular. However, virion-imported human kinases have been shown to specifically contribute to cellular target protein phosphorylation (Nogalski et al., 2007). It will therefore be necessary to further investigate the composition of PP1 holoenzymes in the viral vs. host environment to elucidate the specific function of virus-derived PP1. Manipulation of host metabolism and the cellular stress response starts already at pre-immediate early times with binding and entry of the virus. HCMV manipulates metabolic signaling pathways in a way to uphold features that are beneficial to the virus while inhibiting detrimental effects (Shenk et al., 2014). PP1 inhibition using 1E703 led to disturbance of metabolic signaling already at $2-6 \mathrm{~h}$ postinfection. In a phosphoproteomic analysis and a phosphokinase 
array, many of the 1E7-03-affected signaling pathways were related to cellular stress and metabolic activity (Figure 3). PP1 inhibition even led to an attenuation of global protein translation during HCMV infection (Figure $\mathbf{2 H}$ ). We identified changes in $\mathrm{AMPK} \alpha$ and EEF2 phosphorylation as a possible mechanism of 1E7-03-mediated translation inhibition. AMPK not only regulates fatty acid and glucose metabolism but also modulates protein synthesis and cell growth through the EEF2K/EEF2 and TSC2/mTOR pathways (Johanns et al., 2017). EEF2 itself, which catalyzes the ribosomal movement along the mRNA, is also present in the HCMV virion in its active unphosphorylated form (Figure 4B), but it remains to be determined whether virus-imported EEF2 is of biological relevance. While EEF2 T56 phosphorylation could not be dephosphorylated by PP1 in HFF, we identified PP1 as a potential AMPK $\alpha$ phosphatase (Figures 4E-G), so far only described in mice (Garcia-Haro et al., 2010). siRNA-mediated knockdown of EEF2 kinase or AMPK $\alpha$ attenuated the 1E7-03 mediated effect of viral protein reduction (Figure 5). EEF2K knockdown also showed a trend to reconstitute viral titers late in infection, but this was not statistically significant. AMPK knockdown by itself reduced HCMV titers as already reported by others (Terry et al., 2012). It needs to be added that modulation of a promiscuous phosphatase such as PP1 likely induces many more changes in the cell, AMPK phosphorylation being only one of them.

In the literature, AMPK has been described to play an ambivalent role during HCMV infection, since both its inhibition and activation have been reported to be detrimental for HCMV replication. HCMV infection has been shown to modestly increase total AMPK but not change the amount of phosphorylated AMPK $\alpha$ (Terry et al., 2012). Inhibition of AMPK or its kinase CAMKK2 is known to block the glycolytic activation of the cell, thereby decreasing HCMV viral progeny (McArdle et al., 2012; Terry et al., 2012). On the other hand, the AMPK activating molecule AICAR was also reported to inhibit HCMV immediate early expression (Kudchodkar et al., 2007). In addition, it has been suggested that during very early times of infection, AMPK dephosphorylation might be promoted (Kudchodkar et al., 2007). Our study provides evidence that this dephosphorylation might be mediated by PP1 and suggests a novel layer of AMPK regulation by inhibition of the AMPK/EEF2K/EEF2 axis via PP1 starting very early in infection (Figure 5D). A better understanding of the impact of virus-host interactions on cellular phosphorylation and antiviral responses is of high clinical relevance for the identification of potential broad-spectrum antiviral targets and

\section{REFERENCES}

Ammosova, T., Pietzsch, C. A., Saygideger, Y., Ilatovsky, A., Lin, X., Ivanov, A., et al. (2018). Protein phosphatase 1-targeting small-molecule C31 INHIBITS EBOLA VIRUS replication. J. Infect Dis. 218, S627-S635. doi: 10.1093/infdis/jiy422

Ammosova, T., Platonov, M., Ivanov, A., Kont, Y. S., Kumari, N., Kehn-Hall, K., et al. (2014). 1E7-03, a low MW compound targeting host protein phosphatase-1, inhibits HIV-1 transcription. Br. J. Pharmacol. 171, 5059-5075. doi: 10.1111/bph.12863 drug development. Lastly, this study might help shed light on the therapeutic potential of targeting Ser/Thr phosphatases, which are considered challenging drug targets.

\section{DATA AVAILABILITY STATEMENT}

The mass spectrometry proteomics data have been deposited to the ProteomeXchange Consortium via the PRIDE partner repository with the dataset identifier PXD023598.

\section{AUTHOR CONTRIBUTIONS}

CStec designed the study, performed experiments and data analysis, created the graphs, and wrote the manuscript. AK, LM-H, SM, and FR-R performed experiments and data analysis. M-TK prepared experiments and provided technical assistance. XL performed experiments and contributed to proteomic data analysis. SN contributed essential materials and guidance. CStei designed and supervised the study. All authors critically revised the manuscript.

\section{FUNDING}

This work was funded by the Medical University of Vienna and the Austrian Science Fund (FWF) P33546. This study was also supported by NIH grants to SN (1R01HL125005, 5U54MD007597, and AI117970). CStec is a recipient of a DOC Fellowship of the Austrian Academy of Sciences at the Department of Internal Medicine I of the Medical University of Vienna.

\section{ACKNOWLEDGMENTS}

We thank Thomas Mertens (University Medical Center Ulm, Germany) for providing human forsekin fibroblasts, and Markus Kunze (Center of Brain Research, Medical University of Vienna) for providing $\mathrm{m} 2 \mathrm{~h}$ plasmids and excellent technical guidance.

\section{SUPPLEMENTARY MATERIAL}

The Supplementary Material for this article can be found online at: https://www.frontiersin.org/articles/10.3389/fmicb. 2021.698603/full\#supplementary-material Ashour, A. A., Gurbuz, N., Alpay, S. N., Abdel-Aziz, A. A. H., Mansour, A. M., Huo,
L., et al. (2014). Elongation factor-2 kinase regulates TG2/ $\beta 1$ integrin/Src/uPAR
pathway and epithelial-mesenchymal transition mediating pancreatic cancer
cells invasion. J. Cell Mol. Med. 18, 2235-2251. doi: 10.1111/jcmm.
12361
Bae, J. E., Kang, G. M., Min, S. H., Jo, D. S., Jung, Y. K., Kim,
K., et al. (2019). Primary cilia mediate mitochondrial stress
responses to promote dopamine neuron survival in a Parkinson's
disease model. Cell Death Dis. 10, 1-15. doi: 10.1038/s41419-019-
2184-y 
Baer, A., Shafagati, N., Benedict, A., Ammosova, T., Ivanov, A., Hakami, R. M., et al. (2016). Protein Phosphatase 1 regulates Rift Valley fever virus replication. Antiviral Res. 127, 79-89. doi: 10.1016/j.antiviral.2016.01.007

Britt, W. J. (2010). Human cytomegalovirus: propagation, quantification, and storage. Curr. Protoc. Microbiol. Chapter 14: Unit 14E.3. doi: 10.1002/9780471729259.mc14e03s18

Carey, B. D., Ammosova, T., Pinkham, C., Lin, X., Zhou, W., Liotta, L. A., et al. (2018). Protein phosphatase $1 \alpha$ interacts with venezuelan equine encephalitis virus capsid protein and regulates viral replication through modulation of capsid phosphorylation. J. Virol. 92:e02068. doi: 10.1128/JVI.02068-17

Chen, E. Y., Tan, C. M., Kou, Y., Duan, Q., Wang, Z., Meirelles, G. V., et al. (2013). Enrichr: Interactive and collaborative HTML5 gene list enrichment analysis tool. BMC Bioinformatics. 14:128. doi: 10.1186/1471-2105-14-128

Couté, Y., Kraut, A., Zimmermann, C., Büscher, N., Hesse, A.,-, Bruley, C., et al. (2020). Mass spectrometry-based characterization of the virion proteome, phosphoproteome, and associated kinase activity of human cytomegalovirus. Microorganisms. 8:820. doi: 10.3390/microorganisms 8060820

Davis, M. E., Wang, M. K., Rennick, L. J., Full, F., Gableske, S., Mesman, A. W., et al. (2014). Antagonism of the phosphatase PP1 by the measles virus $\mathrm{V}$ protein is required for innate immune escape of MDA5. Cell Host Microbe 16, 19-30. doi: 10.1016/j.chom.2014.06.007

Dunn, D. M., and Munger, J. (2020). Interplay between calcium and AMPK signaling in human cytomegalovirus infection. Front. Cell. Infect. Microbiol. 10:384. doi: 10.3389/fcimb.2020.00384

Garcia-Haro, L., Garcia-Gimeno, M. A., Neumann, D., Beullens, M., Bollen, M., and Sanz, P. (2010). The PP1-R6 protein phosphatase holoenzyme is involved in the glucose-induced dephosphorylation and inactivation of AMP-activated protein kinase, a key regulator of insulin secretion, in MIN6 $\beta$ cells. FASEB J. 24, 5080-5091. doi: 10.1096/fj.10-166306

Hait, W. N., Wu, H., Jin, S., and Yang, J. M. (2006). Elongation factor-2 kinase: its role in protein synthesis and autophagy. Autophagy 2, 294-296. doi: 10.4161 /auto.2857

Hakki, M., and Geballe, A. P. (2008). Cellular serine/threonine phosphatase activity during human cytomegalovirus infection. Virology 380, 255-263. doi: 10.1016/j.virol.2008.07.028

Hensel, G., Meyer, H., Gärtner, S., Brand, G., and Kern, H. F. (1995). Nuclear localization of the human cytomegalovirus tegument protein pp150 (ppUL32). J. Gen. Virol. 76(Pt 7):1591-601. doi: 10.1099/0022-1317-76-7-1591

Heroes, E., Lesage, B., Görnemann, J., Beullens, M., Van Meervelt, L., and Bollen, M. (2013). The PP1 binding code: a molecular-lego strategy that governs specificity. FEBS J. 280, 584-595. doi: 10.1111/j.1742-4658.2012.08547.x

Hiraga, S., Ly, T., Garzón, J., Horej, Z., Ohkubo, Y., Endo, A., et al. (2017). Human RIF 1 and protein phosphatase 1 stimulate DNA replication origin licensing but suppress origin activation. EMBO Rep. 18, 403-419. doi: $10.15252 /$ embr.201641983

Johanns, M., Pyr dit Ruys, S., Houddane, A., Vertommen, D., Herinckx, G., Hue, L., et al. (2017). Direct and indirect activation of eukaryotic elongation factor 2 kinase by AMP-activated protein kinase. Cell Signal 36, 212-221. doi: 10.1016/j.cellsig.2017.05.010

Kalejta, R. F. (2008). Tegument proteins of human cytomegalovirus. Microbiol. Mol. Biol. Rev. 72, 249-265. doi: 10.1128/MMBR.00040-07

Kudchodkar, S. B., Del Prete, G. Q., Maguire, T. G., and Alwine, J. C. (2007). AMPK-Mediated inhibition of mTOR kinase is circumvented during immediate-early times of human cytomegalovirus infection. J. Virol. 81, 3649-3651. doi: 10.1128/jvi.02079-06

Kunze, M., Malkani, N., Maurer-Stroh, S., Wiesinger, C., Schmid, J. A., and Berger, J. (2015). Mechanistic insights into PTS2-mediated peroxisomal protein import. J. Biol. Chem. 290, 4928-4940. doi: 10.1074/jbc.M114.601575

Li, J., Liu, J., Li, P., Mao, X., Li, W., Yang, J., et al. (2014). Loss of LKB1 disrupts breast epithelial cell polarity and promotes breast cancer metastasis and invasion. J. Exp. Clin. Cancer. Res. 33, 70. doi: 10.1186/s13046-014-0070-0

Li, X., Wilmanns, M., Thornton, J., and Köhn, M. (2013). Elucidating human phosphatase-substrate networks. Sci. Signal. 6:rs10. doi: 10.1126/scisignal.2003203

Li, Y., Zhang, C., Chen, X., Yu, J., Wang, Y., Yang, Y., et al. (2011). ICP34.5 Protein of herpes simplex virus facilitates the initiation of protein translation by bridging eukaryotic initiation factor $2 \alpha(\mathrm{eIF} 2 \alpha)$ and protein phosphatase 1 . J. Biol. Chem. 286, 24785-24792. doi: 10.1074/jbc.M111.232439
Lin, X., Ammosova, T., Choy, M. S., Pietzsch, C. A., Ivanov, A., Ahmad, A., et al. (2019). Targeting the non-catalytic RVxF site of protein phosphatase1 with small molecules for ebola virus inhibition. Front. Microbiol. 10:2145. doi: 10.3389/fmicb.2019.02145

Lin, X., Kumari, N., DeMarino, C., Kont, Y. S., Ammosova, T., Kulkarni, A., et al. (2017). Inhibition of HIV-1 infection in humanized mice and metabolic stability of protein phosphatase-1-targeting small molecule 1E7-03. Oncotarget 8, 76749-76769. doi: 10.18632/oncotarget.19999

Livak, K. J., and Schmittgen, T. D. (2001). Analysis of relative gene expression data using real-time quantitative PCR and the 2- $\Delta \Delta$ CT method. Methods 25, 402-408. doi: 10.1006/meth.2001.1262

McArdle, J., Moorman, N. J., and Munger, J. (2012). HCMV targets the metabolic stress response through activation of AMPK whose activity is important for viral replication. PLoS Pathog. 8:e1002502. doi: 10.1371/journal.ppat.1002502

McKinney, C., Zavadil, J., Bianco, C., Shiflett, L., Brown, S., and Mohr, I. (2014). Global reprogramming of the cellular translational landscape facilitates cytomegalovirus replication. Cell Rep. 6, 9-17. doi: 10.1016/j.celrep.2013.11.045

Michelson, S., Turowski, P., Picard, L., Goris, J., Landini, M. P., Topilko, A., et al. (1996). Human cytomegalovirus carries serine/threonine protein phosphatases PP1 and a host-cell derived PP2A. J. Virol. 70, 1415-1423.

Moorman, N. J., Cristea, I. M., Terhune, S. S., Rout, M. P., Chait, B. T., and Shenk, T. (2008). Human cytomegalovirus protein UL38 inhibits host cell stress responses by antagonizing the tuberous sclerosis protein complex. cell host microbe. Cell Press 3, 253-262. doi: 10.1016/j.chom.2008. 03.002

Munday, R. (2013). Is protein phosphatase inhibition responsible for the toxic effects of okadaic Acid in animals? Toxins (Basel) 5, 267-285. doi: 10.3390/toxins5020267

Nekhai, S., Jerebtsova, M., Jackson, A., and Southerland, W. (2007). Regulation of HIV-1 transcription by protein phosphatase 1. Curr. HIV Res. 5, 3-9. doi: $10.2174 / 157016207779316279$

Nogalski, M. T., Podduturi, J. P., DeMeritt, I. B., Milford, L. E., and Yurochko, A. D. (2007). The human cytomegalovirus virion possesses an activated casein kinase II that allows for the rapid phosphorylation of the inhibitor of NF- B, I B. J. Virol. 81, 5305-5314. doi: 10.1128/JVI.02382-06

Pattyn, F., Speleman, F., De Paepe, A., and Vandesompele, J. (2003). RTPrimerDB: the real-time PCR primer and probe database. Nucleic Acids Res. 31, 122-123. doi: 10.1093/nar/gkg011

Rebelo, S., Santos, M., Martins, F., da Cruz e Silva, E. F., and da Cruz e Silva, O. A. B. (2015). Protein phosphatase 1 is a key player in nuclear events. Cell Signal. 27, 2589-2598. doi: 10.1016/j.cellsig.2015.08.007

Reyda, S., Tenzer, S., Navarro, P., Gebauer, W., Saur, M., Krauter, S., et al. (2014). The Tegument Protein pp65 of human cytomegalovirus acts as an optional scaffold protein that optimizes protein uploading into viral particles. J. Virol. 88, 9633-9646. doi: 10.1128/JVI.01415-14

Rieder, F. J. J., Gröschel, C., Kastner, M.-T., Kosulin, K., Laengle, J., Zadnikar, R., et al. (2017a). Human cytomegalovirus infection downregulates vitaminD receptor in mammalian cells. J. Steroid Biochem. Mol. Biol. 165, 356-362. doi: 10.1016/j.jsbmb.2016.08.002

Rieder, F. J. J., Kastner, M.-T., Hartl, M., Puchinger, M. G., Schneider, M., Majdic, O., et al. (2017b). Human cytomegalovirus phosphoproteins are hypophosphorylated and intrinsically disordered. J. Gen. Virol. 98, 471-485. doi: 10.1099/jgv.0.000675

Schmittgen, T. D., and Livak, K. J. (2008). Analyzing real-time PCR data by the comparative CT method. Nat. Protoc. 3, 1101-1108. doi: 10.1038/nprot.2008.73

Shenk, T., and Alwine, J. C. (2014). Human cytomegalovirus: coordinating cellular stress, signaling, and metabolic pathways. Annu. Rev. Virol. 1, 355-374. doi: 10.1146/annurev-virology-031413-085425

Shi, Y. (2009). Serine/threonine phosphatases: mechanism through structure. Cell 139, 468-484. doi: 10.1016/j.cell.2009.10.006

Soroceanu, L., Akhavan, A., and Cobbs, C. S. (2008). Platelet-derived growth factor-alpha receptor activation is required for human cytomegalovirus infection. Nature 455, 391-395. doi: 10.1038/nature07209

Spandidos, A., Wang, X., Wang, H., and Seed, B. (2010). PrimerBank: a resource of human and mouse PCR primer pairs for gene expression detection and quantification. Nucleic Acids Res. 38, D792-D799. doi: 10.1093/nar/gkp1005

Sweet, C. (1999). The pathogenicity of cytomegalovirus. FEMS Microbiol. Rev. 23, 457-482. doi: 10.1111/j.1574-6976.1999.tb00408.x 
Swingle, M., Ni, L., and Honkanen, R. E. (2007). Small-molecule inhibitors of ser/thr protein phosphatases: Specificity, use and common forms of abuse. Methods Mol. Biol. 365, 23-38. doi: 10.1385/1-59745-267-X:23

Terhune, S. S., Schroer, J., and Shenk, T. (2004). RNAs are packaged into human cytomegalovirus virions in proportion to their intracellular concentration. J. Virol. 78, 10390-10398. doi: 10.1128/JVI.78.19.10390-10398.2004

Terry, L. J., Vastag, L., Rabinowitz, J. D., and Shenk, T. (2012). Human kinome profiling identifies a requirement for AMP-activated protein kinase during human cytomegalovirus infection. Proc. Natl. Acad. Sci. U.S.A. 109, 3071-3076. doi: 10.1073/pnas.1200494109

Tigabu, B., Ramanathan, P., Ivanov, A., Lin, X., Ilinykh, P. A., Parry, C. S., et al. (2018). Phosphorylated VP30 of marburg virus is a repressor of transcription. J. Virol. 92:e00426-18. doi: 10.1128/JVI.00426-18

Untergasser, A., Nijveen, H., Rao, X., Bisseling, T., Geurts, R., and Leunissen, J. A. M. (2007). Primer3Plus, an enhanced web interface to Primer3. Nucleic Acids Res. 35, W71-W74. doi: 10.1093/nar/gkm306

Varnum, S. M., Streblow, D. N., Monroe, M. E., Smith, P., Auberry, K. J., PasaTolic, L., et al. (2004). Identification of proteins in human cytomegalovirus (HCMV) particles: the HCMV proteome. J. Virol. 78, 10960-10966. doi: 10.1128/JVI.78.20.10960-10966.2004

Vincent, H. A., Ziehr, B., and Moorman, N. J. (2016). Human cytomegalovirus strategies to maintain and promote mRNA translation. Viruses 8:97. doi: $10.3390 / \mathrm{v} 8040097$
Zhang, F., Moon, A., Childs, K., Goodbourn, S., and Dixon, L. K. (2010). The African swine fever virus DP71L protein recruits the protein phosphatase 1 catalytic subunit to dephosphorylate eIF2 $\alpha$ and inhibits CHOP induction but is dispensable for these activities during virus infection. J. Virol. 84, 10681-10689. doi: 10.1128/JVI. 01027-10

Conflict of Interest: A patent application on 1E7-03 activity against HCMV has been filed by Howard University with SN and CStei as co-inventors based on parts of the data in this publication.

The remaining authors declare that the research was conducted in the absence of any commercial or financial relationships that could be construed as a potential conflict of interest.

Copyright (c) 2021 Stecher, Marinkov, Mayr-Harting, Katic, Kastner, RiederRommer, Lin, Nekhai and Steininger. This is an open-access article distributed under the terms of the Creative Commons Attribution License (CC BY). The use, distribution or reproduction in other forums is permitted, provided the original author(s) and the copyright owner(s) are credited and that the original publication in this journal is cited, in accordance with accepted academic practice. No use, distribution or reproduction is permitted which does not comply with these terms. 